\title{
Coronary Artery Bypass Surgery for Patients Presenting with Ventricular Arrhythmias: Propensity Matched Early and Late Outcome
}

\author{
Ahmed M. Habib1,2*, Azar Hussain1, Martin Jarvis', Alexander Cale1, Michael Cowen1, \\ Dumbor Ngaage ${ }^{1}$, Mubarak Chaudhry ${ }^{1}$, Mahmoud Loubani ${ }^{1}$ \\ ${ }^{1}$ Cardiothoracic Surgery, Castle Hill Hospital, Cottingham, UK \\ ${ }^{2}$ Cardiothoracic Surgery, Ain Shams University Hospitals, Cairo, Egypt \\ Email: `habibmos@gmail.com
}

How to cite this paper: Habib, A.M., Hussain, A., Jarvis, M., Cale, A., Cowen, M., Ngaage, D., Chaudhry, M. and Loubani, M. (2018) Coronary Artery Bypass Surgery for Patients Presenting with Ventricular Arrhythmias: Propensity Matched Early and Late Outcome. World Journal of Cardiovascular Surgery, 8, 40-50.

https://doi.org/10.4236/wjcs.2018.82005

Received: January 7, 2018

Accepted: February 10, 2018

Published: February 13, 2018

Copyright $\odot 2018$ by authors and Scientific Research Publishing Inc. This work is licensed under the Creative Commons Attribution International License (CC BY 4.0).

http://creativecommons.org/licenses/by/4.0/

\begin{abstract}
Objectives: Patients with ischemic ventricular arrhythmia (IVA) in the form of fibrillation or tachycardia represent a surgical challenge. Evidence in the literature suggests that ventricular arrhythmia threatens survival even after cardiac surgery. We aim to review the results of our patients presenting with IVA with regard to short and long term outcome following cardiac surgery. Methods: This was a retrospective study of data entered prospectively into our cardiac surgical database between January 1999 and September 2015. A total of 9609 patients underwent Cardiac Surgery which included 54 patients after surviving IVA. The short- and long-term outcomes were compared to a propensity matched group. Actuarial survival was calculated using Kaplan Meier analysis. Results: The 54 study group patients were propensity matched on a 1:2 basis with a control group of non-IVA $(\mathrm{n}=108)$. The baseline preoperative characteristics and risk factors were similar between the 2 groups and all cases underwent CABG only. Univariate analysis showed pacing postoperatively ( 33.3 vs $66.7 \% ; \mathrm{p}=0.001$ ) and postoperative ventricular arrhythmia ( 10 vs $22.2 \% ; \mathrm{p}=0.039$ ) to be significantly higher in the IVA group. Cox-multivariate analysis showed postoperative ventricular arrhythmia in either group (Hazard ratio $=1.5$ ) to be the only significant factor to impact mortality $(\mathrm{p}<0.001)$. Long term survival was not significantly different between the two groups (10.4; CI: $9.08-11.75$ vs 9.3; CI: $7.61-11.01$ yrs, $\mathrm{p}=$ 0.3 ). Conclusion: Cardiac surgery on patients presenting with IVA can be performed safely yielding short and long term results equivalent to non-IVA cases. These patients should not be denied surgery with consideration of good long term outcome.
\end{abstract}




\section{Keywords}

Ischemic Ventricular Arrhythmia (IVA), Ventricular Fibrillation (VF), Implantable Cardioverter (ICD), Coronary Artery Disease (CAD)

\section{Introduction}

Arrhythmias and ischemic heart disease comprise a significant percentage of sudden cardiac death especially in the older population [1] [2]. Patients with ischemic heart disease presenting with ventricular arrhythmias (VA) represent a high risk population compared to the rest of the patients undergoing surgical revascularisation [3]. Randomised control trial on this subgroup of patients is not feasible due to ethical and clinical restraints and although a number of studies assessed short and long term outcomes of these ischemic patients presenting with VAs none seems to have a proper control group [4] [5] [6]. The absence of a control group raises concerns over any conclusions. In this study we aim to assess the short and long term outcomes of patients undergoing surgical revascularisation following presentation with VA against an equivalent control group by propensity matching. Propensity matching empowers the retrospective study. It allows comparable results and conclusions to those of a randomised controlled study [7].

Given the increased incidence of annual VA (8\%) even after revascularisation [8], we also reviewed the impact of completeness of revascularisation and ICD insertion on these outcomes in our data.

\section{Methods}

\subsection{Design}

This is a retrospective study of all patients that underwent coronary artery bypass surgery (CABG) between January 1999 and September 2015 and included in our database at Hull and East Yorkshire Hospitals NHS Trust was examined. We identified a total of 9609 patients who underwent CABG with 54 (5.62\%) of them having survived an ischemic ventricular arrhythmia (IVA). Operative mortality was defined as occurring during the operative hospitalization or within 30 days of operation for discharged patients. The preoperative characteristics were as defined by the EuroSCORE I criteria [9].

Other secondary outcomes were: Perioperative intra-aortic balloon pump, sternal resuturing, postoperative myocardial infarction, postoperative arrhythmias and permanent pacing, pulmonary complications, wound infections, gastrointestinal complications and multiorgan failure.

\subsection{Propensity Score Matching}

Using "R" program [10]; patient's preoperative characteristics (Age, gender, BMI), comorbidities (neurologic, renal, pulmonary), Ejection fraction, urgency of op- 
eration and logistic EuroSCORE were used to develop a score (propensity score) for each case. The 54 post IVA patients were propensity matched to patients that underwent CABG without prior IVA in a 1:2 ratio $(n=108)$.

Individual informed consent was waived due to the fact that the data was already available for clinical and research purposes. Furthermore, the data was in a format that would not allow any individual patient to be identified (anonymised).

\subsection{Statistical Analysis}

1) Univariate analysis:

Categorical data are summarized using percentages. Continuous data are presented as the mean value ( \pm standard deviation). Categorical data were compared by Chi-squared test. Continuous data were tested against "Normal" Plot and "Q-Q" plots; those of normal distribution were compared using student t-test while non-normal distributed data were compared by "Mann-Whitney test".

2) Multivariate analysis:

Cox multivariate analysis was used to identify the impact of the significant factors from the univariate analysis on the long term survival.

\subsection{Long Term Survival}

Long term survival for each group was analysed using Kaplan-Meier curves and then compared by the log rank test to calculate the p-value.

A p-value of $<0.05$ was considered statistically significant. The $95 \%$ confidence interval is calculated according to Brookmeyer \& Crowley.

Statistical analyses were performed using MedCalc for Windows, version 13.1.2 (MedCalc Software, Ostend, Belgium).

\section{Results}

Baseline criteria:

The baseline criteria for all the cases that underwent cardiac surgery in our unit are shown in Table 1.

Study flow chart:

The flow chart (Figure 1) shows how the study and the control groups were obtained and their relevant sizes.

Propensity scoring and matching:

Using R computer programming each patient from the patient population was given a score depending on the factors mentioned in the methods section. Based on the score, each patient from the study group was matched with the closest two patients from the control group (Figure 2).

Univariate analysis:

Analysis of the pre-, intra- and postoperative factors identified post operative VF and permanent pacemaker insertion were significantly higher in the study group (Table 2). 
Table 1. Baseline criteria for the database $(n=9609)$. Absolute numbers (percentage of total) or mean \pm standard deviation $(\mathrm{SD})$.

\begin{tabular}{|c|c|}
\hline \multicolumn{2}{|c|}{ Preoperative criteria } \\
\hline Age & $65.8 \pm 10.2$ \\
\hline Gender (male) & $6939(72.2 \%)$ \\
\hline NYHA class (4) & $369(3.8 \%)$ \\
\hline CCS class $(4)$ & $995(10.4 \%)$ \\
\hline Hypertensive & $7248(75.4 \%)$ \\
\hline Diabetic & $1705(17.7 \%)$ \\
\hline $\mathrm{Ex} /$ current smoker & $6148(64.0 \%)$ \\
\hline Patients on long term inhalers & $1163(12.1 \%)$ \\
\hline Preoperative renal dysfunction & $217(2.3 \%)$ \\
\hline Neurologic dysfunction & $95(1.0 \%)$ \\
\hline Peripheral vascular disease & $952(9.9 \%)$ \\
\hline Preoperative inotropic support & $87(0.9 \%)$ \\
\hline Preoperative nitrate infusion & $532(5.5 \%)$ \\
\hline Preoperative ventilation & $48(0.5 \%)$ \\
\hline Preoperative cardiogenic shock & $65(0.7 \%)$ \\
\hline Preoperative MI & $3174(33.0 \%)$ \\
\hline Left ventricular ejection fraction (Poor) & $565(5.9 \%)$ \\
\hline Preoperative VF/VT & $54(0.6 \%)$ \\
\hline Redo sternotomy & $556(5.8 \%)$ \\
\hline BMI & $28.1 \pm 4.5$ \\
\hline Logistic EuroSCORE & $5.3 \pm 8$ \\
\hline \multicolumn{2}{|c|}{ Operative Criteria } \\
\hline Urgency (emergency) & $193(2 \%)$ \\
\hline Perioperative IABP & $93(1.0 \%)$ \\
\hline Not isolated CABG & $3144(32.7 \%)$ \\
\hline Off bypass CABG & $469(4.9 \%)$ \\
\hline Perfusion time & $71.2 \pm 34.7$ \\
\hline Cross clamp time (min) & $41.9 \pm 22.8$ \\
\hline \multicolumn{2}{|c|}{ Post operative criteria } \\
\hline Average hospital stay (days) & $9.4 \pm 11.1$ \\
\hline Postoperative permanent stroke & $100(1.0 \%)$ \\
\hline low cardiac output (requiring inotropes, IABP or VAD) & $3081(32.1 \%)$ \\
\hline Re-exploration & $416(4.3 \%)$ \\
\hline ITU readmission & $367(3.8 \%)$ \\
\hline New postoperative dialysis & $152(1.6 \%)$ \\
\hline In-hospital mortality and 30 day mortality & $307(3.2 \%)$ \\
\hline
\end{tabular}




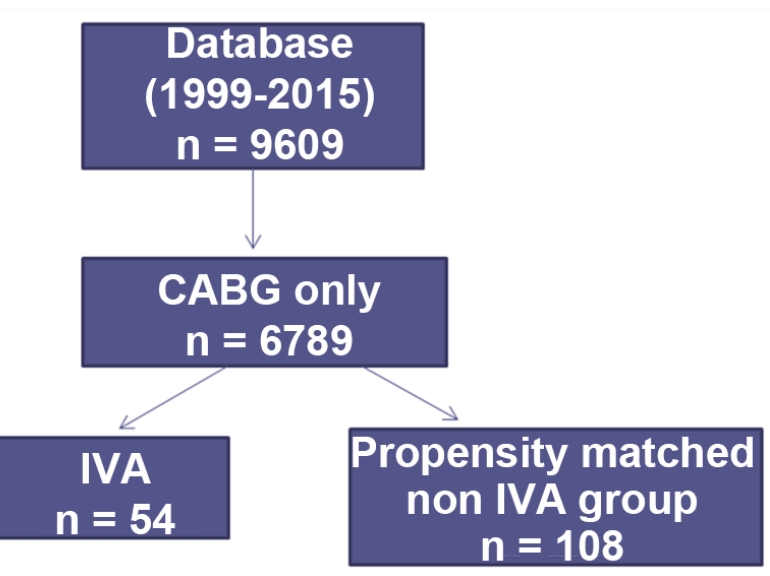

Figure 1. Flow chart showing the control and study groups.

Raw Treated

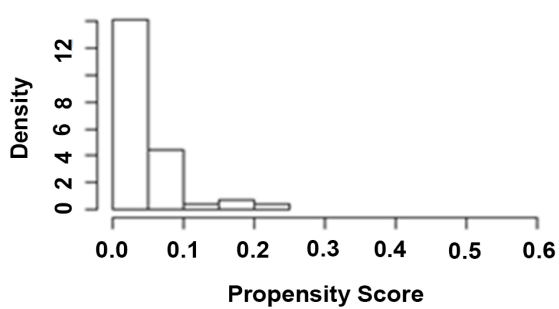

Raw Control

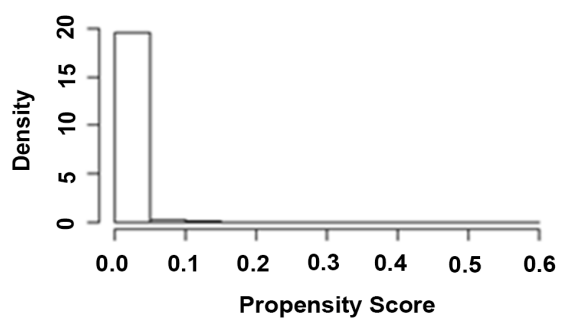

Mached Treated
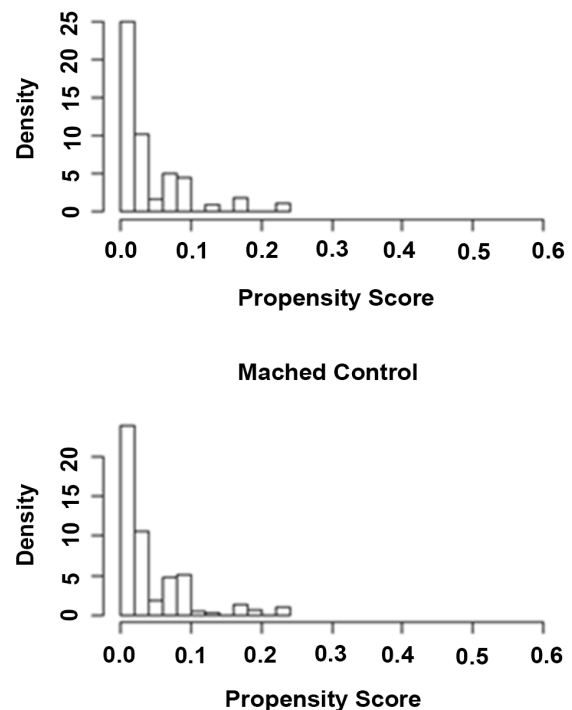

Distribution of Propensity Scores

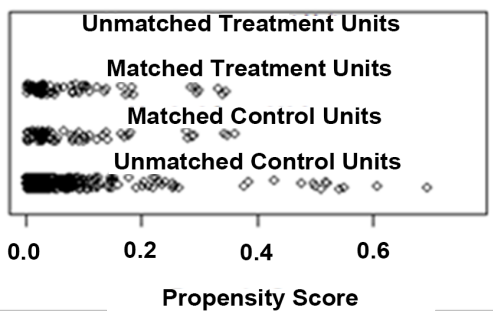

Figure 2. Bar charts and dot graph showing the propensity matched control and study groups.

Cox multivariate analysis (predictors of long term survival):

Multivariate analysis revealed that the only factor impacting on in hospital mortality was postoperative VF (HR 1.5) as seen in Table 2.

Significantly higher in the study group. Multivariate analysis showing Postoperative VF the only factor impacting on in-hospital mortality. 
Table 2. Univariate analysis showing postoperative VF and permanent pacing were significantly higher in the study group. Multivariate analysis showing Postoperative VF the only factor impacting on in-hospital mortality.

\begin{tabular}{|c|c|c|c|}
\hline Variable & $\begin{array}{l}\text { Study group } \\
(\text { IVA } \mathrm{n}=54)\end{array}$ & $\begin{array}{c}\text { Control group } \\
\text { (Non IVA } \mathrm{n}=108)\end{array}$ & $\mathrm{p}$ value \\
\hline Age (Mean) & 67.1852 & 68.2963 & 0.454 \\
\hline Gender $(\mathrm{M})$ & $81.5 \%$ & $67.6 \%$ & 0.064 \\
\hline NYHA IV & $9.3 \%$ & $10.2 \%$ & 0.330 \\
\hline Previous MI & $66.7 \%$ & $68.5 \%$ & 0.815 \\
\hline $\begin{array}{l}\text { Preoperative unstable angina } \\
\text { (within } 31 \mathrm{~d} \text { ) }\end{array}$ & $1.9 \%$ & 0 & 0.157 \\
\hline Previous operation & $7.4 \%$ & $6.5 \%$ & 0.557 \\
\hline Diabetes & $24.1 \%$ & 33.3 & 0.228 \\
\hline Hypertension & 77.8 & 63 & 0.058 \\
\hline Preoperative GI morbidity & 18.5 & $14.8 \%$ & 0.546 \\
\hline Preoperative inotropes & 1.9 & 0 & 0.157 \\
\hline Preoperative nitrates/heparin & 20.4 & 29.6 & 0.210 \\
\hline Preoperative congestive HF & $37 \%$ & $26.9 \%$ & 0.185 \\
\hline Cardiogenic shock & 0 & 1.9 & 0.316 \\
\hline Preoperative ventilation & 1.9 & 0.9 & 0.616 \\
\hline Logistic EuroSCORE & 13.1 & 10.68 & 0.188 \\
\hline $\mathrm{CPB}$ & $94.4 \%$ & $88.9 \%$ & 0.252 \\
\hline $\mathrm{X}$ clamp time (mean-min) & 27.5 & 27.9 & 0.860 \\
\hline Bypass (mean-min) & 58 & 60.2 & 0.664 \\
\hline Reopening for bleeding & 3.7 & 4.6 & 0.785 \\
\hline Low COP & 66.7 & 56.5 & 0.214 \\
\hline ITU recidivism & 3.7 & 4.6 & 0.785 \\
\hline Renal complication & 0 & $2.8 \%$ & 0.218 \\
\hline Neurologic complication & 0 & 0.9 & 0.480 \\
\hline Post op stay (d) & 10.5 & 10.13 & 0.851 \\
\hline No. Of diseased vessels & 2.57 & 2.7 & 0.253 \\
\hline LMS & $41.7 \%$ & $42.6 \%$ & 0.911 \\
\hline Distal anastomoses & 2.54 & 2.58 & 0.694 \\
\hline Perioperative IABP & 5.6 & 13 & 0.148 \\
\hline Sternal resuturing & $1.9 \%$ & $1.9 \%$ & 1.000 \\
\hline Perioperative $\mathrm{Q}$ wave & 0 & $0.9 \%$ & 0.480 \\
\hline Postoperative MI & 0 & $3.7 \%$ & 0.153 \\
\hline Postoperative Arrhythmia (VF) & $22.2 \%$ & $10.2 \%$ & 0.039 \\
\hline Postoperative AF & $25.9 \%$ & $31.5 \%$ & 0.467 \\
\hline Postoperative PPM & $66.7 \%$ & $28.4 \%$ & 0.001 \\
\hline Pulmonary complications & $22.2 \%$ & $23.1 \%$ & 0.895 \\
\hline Postoperative GI complications & $5.6 \%$ & $6.5 \%$ & 0.818 \\
\hline Multi organ failure & $0 \%$ & $2.8 \%$ & 0.218 \\
\hline In-hospital mortality & $3.7 \%$ & $10.2 \%$ & 0.154 \\
\hline \multicolumn{4}{|c|}{ Cox proportional-hazards regression } \\
\hline Variable & Hazard Ratio & $95 \%$ CI & $\mathrm{p}$ value \\
\hline Postoperative Arrhythmia (VF) & 1.524 & 1.268 to 1.832 & $<0.001$ \\
\hline
\end{tabular}


Long term survival:

Kaplan Meier analysis of the long term survival at 15 years postoperatively showed 7/108 (control group) versus 6/54 (study group) alive. The median survival was 13 (control group) and 10 years (study group). This was not significant by $\log$ rank test $(\mathrm{p}=0.33)$ as demonstrated in Figure 3.

Subgroup analysis of Patients with persistent VA in the study group:

$12(22.2 \%)$ patients in the IVA group had postoperative VF. 2 died in hospital (No EPS performed). 5/10 discharged patients had ICDs inserted (Mean 5.86 years survival). 3/10 discharged did not require ICD (Mean 5.66 years survival). 2/10 needed PPM (Mean 2.85 years survival). The relation between ICD/PPM insertion and LV function (in patients that had postoperative VF and were discharged home alive) is shown in Table 3.

The ratio between the extent of coronary artery disease to number of bypass grafts was as follows:

Preoperative sinus rhythm and postoperative non-VA: 0.95 , preoperative sinus rhythm and postoperative VA: 1.03, preoperative IVA and postoperative non-VA: 0.99 and preoperative IVA with postoperative IVA: 0.97.

\section{Discussion}

VAs are a fatal complication of ischemic heart disease. Many earlier studies claimed better short [3] [11] and long term survival following revascularisation [12]. However, these studies failed to compare this outcome with an "equivalent" control group with suboptimal deduction of conclusions.

The difference in the preoperative characteristics between the database and the propensity matched control group highlights the relevance of performing propensity matching, allowing comparison between homogenous groups, not only performing a similar operative procedure, but with similar characteristics.

To the best of our knowledge, this is the first study to compare the short and long term outcomes following surgical revascularisation with a similar population, risk profile-wise; by propensity scoring and matching. We shall base our discussion on the following questions:

1) Ischemic patients with preoperative VA have up to $8 \%$ annual recurrence of their VA (MADT-CRT) [11] even following there revascularisation. Should this fact impact on conduit choice and completion of grafting (e.g., arterial revascularisation)?

2) With such a high risk profile, rapid surgical revascularisation of the culprit lesions; as performed in primary PCI, should suffice and allow these high risk patients to be discharged home from a quick operation rather than end up with prolonged ITU stay and in-hospital mortality while the remaining CAD may be dealt with by hybrid PCI?

The two groups had similar short term outcomes (except for a higher incidence of postoperative VA and pacemaker insertion). There hospital stay was similar (9 days) which was either due to prolonged ITU stay (from Inotropic, IABP, respiratory and renal causes) and ward stay (due to wound break down 


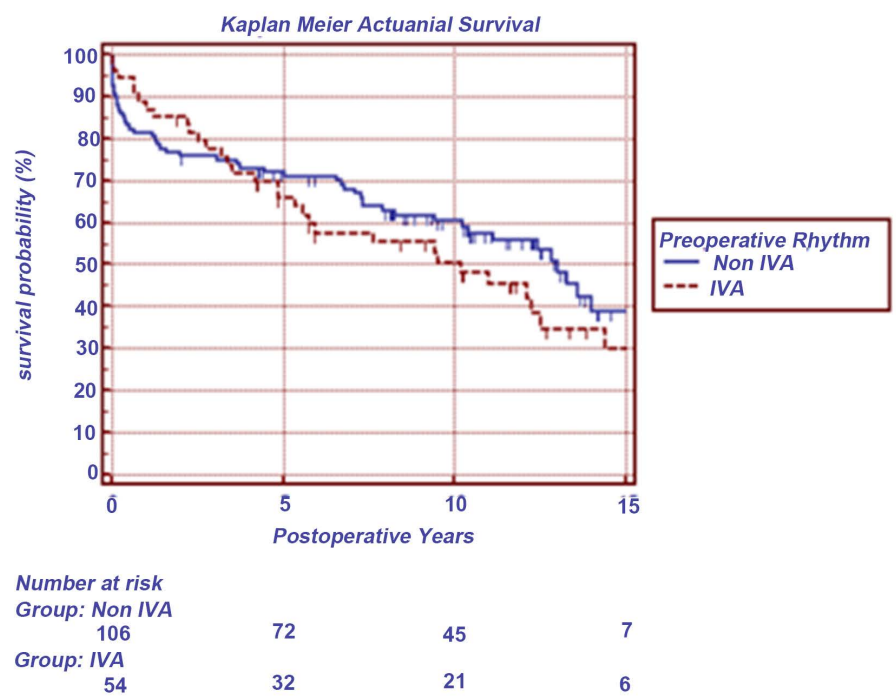

\begin{tabular}{|c|c|c|c|}
\hline Factor & $95 \% \mathrm{Cl}$ for the mean & Median & $95 \% \mathrm{Cl}$ for the median \\
\hline Control group & 9.08 to 11.75 & 12.98 & 10.20 to 13.98 \\
\hline Study group & 7.61 to 11.01 & 10.17 & 5.54 to 14.37 \\
\hline \multicolumn{4}{|c|}{ Comparison of survival curves (Log rank test) } \\
\hline \multicolumn{2}{|c|}{ Significance } & $P=0.33$ & \\
\hline
\end{tabular}

Figure 3. Kaplan Meier curves for the control and the study groups showing no significant difference in the long term survival.

Table 3. Relation between postoperative VF (in the IVA group) and LV function.

\begin{tabular}{cccc}
\hline Discharged IVA patients that had postoperative VF & Good LV & Fair LV & Poor LV \\
\hline 3 no PPM & 1 & 1 & 1 \\
5 ICD & 0 & 1 & 1 \\
2 VVI/DDD & 0 & 1 \\
\hline
\end{tabular}

and infection). Both groups had complete revascularisation (Table 2). In hospital mortality for both groups was statistically similar $(\mathrm{p}=0.15)$. Hence; prolonged bypass and cross clamp time for the sake of adequate revascularisation has not impacted negatively on the short term outcomes.

Long term survival was similar between the control and study group ( $\mathrm{p}=$ 0.33). From the significant factors on univariate analysis, only persistent postoperative VA significantly affected long term survival (HR 1.5) in the multivariate analysis. Causes of postoperative VA are multiple and interrelated: electrolyte disturbance, poor perfusion secondary to low cardiac output, inadequate revascularisation, arrhythmogenic inotropes and even genetic [11]. It is difficult to diagnose the exact cause in most cases and some of these causes are unavoidable, such as genetic predisposition. The most important avoidable factor in 
theatres is inadequate revascularisation which we investigated in more detail by comparing the number of ischemic vessels with the number of grafts in the various subgroups (Table 2 and the last paragraph in the results section) and have not found any difference between the patients that had postoperative VA from the study and control groups as compared to those that had no postoperative VA in both groups. Hence we again conclude that complete revascularisation and choice of conduits should not be jeopardised as patients with preoperative VA have a similar long term survival equivalent to high risk non VA patients. Other studies have suggested the relevance of surgical revascularisation over ICD insertion [13].

All patients that needed postoperative ICD had impaired LV but one. The patient with a good LV underwent ICD insertion 1 month postoperatively based on electrophysiologic studies performed preoperatively. This was prior to the recommendations of MADIT-CRT and SOLVD in 2006 [11] [13]-[18], which stated that the benefits of ICD insertion are after 6 months and a significant proportion of patients, especially those with preserved LV, will remodel and avoid the need for an ICD during this period. Also the mean survival of patients with postoperative VF in the study group that needed an ICD (5.86 years) was similar to those that did not need an ICD (5.66 years). This highlights that even with persistent aetiologies of post operative VA that cannot be reversed, long term survival may be preserved with ICD insertion [12]. The 2 patients that needed postoperative pacing had a shorter mean survival (2.85 years). We could not identify the reason for this and the causes of death could not be identified weather cardiac or non cardiac.

\section{Strengths \& Limitations}

Propensity scoring and matching allowed us to compare the effect of treatment (surgical revascularisation) on observational data. The advantage of using a linear combination of covariates for a single score allows balancing a test group with a control group without losing a large number of observations (cases). In our case the "pool" of data allowed a "greedy" match for the chosen confounding variables.

One disadvantage is that the matching is only for the chosen variables and the rest of the risk factors and comorbidities remain unmatched. Nevertheless, PSM has been assessed by other studies to validate the effect of treatment on observational data [7] [19] [20].

The intrinsic limitations of selection bias are inherent to all observational data. Also, failure to attain the cause related mortalities in long term studies is a common drawback for long term studies.

\section{Conclusions}

1) Coronary Artery Bypass surgery on patients presenting with IVA can be performed safely yielding short and long term results equivalent to non-IVA 
cases.

2) Persistence of Postoperative Ventricular Fibrillation is the single predictor for long term mortality in this population.

3) Cardiology referral to assess the need for ICD insertion is essential postoperatively.

These patients should not be denied surgery with consideration of good long term outcome.

\section{Funding Statement}

There is no funding to declare.

\section{Conflicts of Interest Statement}

There is no conflict of interest to declare.

\section{References}

[1] Niemeijer, M.N., van den Berg, M.E., Leening, M.J.G., Hofman, A., Franco, O.H., Deckers, J.W., et al. (2015) Declining Incidence of Sudden Cardiac Death from 1990-2010 in a General Middle-Aged and Elderly Population: The Rotterdam Study. Heart Rhythm, 12, 123-129. https://doi.org/10.1016/j.hrthm.2014.09.054

[2] Eckart, R.E., Shry, E.A., Burke, A.P., McNear, J.A., Appel, D.A., Castillo-Rojas, L.M., et al. (2011) Sudden Death in Young Adults: An Autopsy-Based Series of a Population Undergoing Active Surveillance. Journal of the American College of Cardiology, 58, 1254-1261. https://doi.org/10.1016/j.jacc.2011.01.049

[3] Task Force Members, Windecker, S., Kolh, P., Alfonso, F., Collet, J.-P., Cremer, J., et al. (2014) 2014 ESC/EACTS Guidelines on Myocardial Revascularization: The Task Force on Myocardial Revascularization of the European Society of Cardiology (ESC) and the European Association for Cardio-Thoracic Surgery (EACTS) Developed with the Special Contribution of the European Association of Percutaneous Cardiovascular Interventions (EAPCI). European Heart Journal, 35, 2541-2619.

https://doi.org/10.1093/eurheartj/ehu278

[4] Kaiser, G.A., et al. (2018) Role of Coronary Artery Surgery in Patients Surviving Unexpected Cardiac Arrest.

http://www.surgjournal.com/article/0039-6060(75)90201-9/fulltext

[5] Autschbach, R., Falk, V., Gonska, B.D. and Dalichau, H. (1994) The Effect of Coronary Bypass Graft Surgery for the Prevention of Sudden Cardiac Death: Recurrent Episodes after ICD Implantation and Review of Literature. Pacing and Clinical Electrophysiology, 17, 552-558. https://doi.org/10.1111/j.1540-8159.1994.tb01425.x

[6] Ngaage, D.L., Cale, A.R.J., Cowen, M.E., Griffin, S. and Guvendik, L. (2008) Early and Late Survival after Surgical Revascularization for Ischemic Ventricular Fibrillation/Tachycardia. The Annals of Thoracic Surgery, 85, 1278-1281.

https://doi.org/10.1016/j.athoracsur.2007.12.035

[7] Dahabreh, I.J., Sheldrick, R.C., Paulus, J.K., Chung, M., Varvarigou, V., Jafri, H., et al. (2012) Do Observational Studies Using Propensity Score Methods Agree with Randomized Trials? A Systematic Comparison of Studies on Acute Coronary Syndromes. European Heart Journal, 33, 1893-1901.

https://doi.org/10.1093/eurheartj/ehs114

[8] Barsheshet, A., Goldenberg, I., Moss, A.J., Huang, D.T., Zareba, W., McNitt, S., et 
al. (2011) Effect of Elapsed Time from Coronary Revascularization to Implantation of a Cardioverter Defibrillator on Long-Term Survival in the MADIT-II Trial. Journal of Cardiovascular Electrophysiology, 22, 1237-1242. https://doi.org/10.1111/j.1540-8167.2011.02096.x

[9] Nashef, S.A., Roques, F., Michel, P., Gauducheau, E., Lemeshow, S. and Salamon R. (1999) European System for Cardiac Operative Risk Evaluation (EuroSCORE). European Journal of Cardio-Thoracic Surgery, 16, 9-13. https://doi.org/10.1016/S1010-7940(99)00134-7

[10] Hornik, K. (2018) R FAQ. https://cran.r-project.org/doc/FAQ/R-FAQ.html\#What-is-R_003f

[11] Gorenek, B. (2015) Cardiac Arrhythmias in Acute Coronary Syndromes: Position Paper from the Joint EHRA, ACCA, and EAPCI Task Force. EuroIntervention, 10, 1095-1108. https://www.ncbi.nlm.nih.gov/pubmed/25169596

[12] Varnauskas, E. (1988) Twelve-Year Follow-up of Survival in the Randomized European Coronary Surgery Study. The New England Journal of Medicine, 319 , 332-337. https://doi.org/10.1056/NEJM198808113190603

[13] Bigger, J.T. (1997) Prophylactic Use of Implanted Cardiac Defibrillators in Patients at High Risk for Ventricular Arrhythmias after Coronary-Artery Bypass Graft Surgery. The New England Journal of Medicine, 337, 1569-1575.

[14] Velazquez, E.J., Lee, K.L., Deja, M.A., Jain, A., Sopko, G., Marchenko, A., et al. (2011) Coronary-Artery Bypass Surgery in Patients with Left Ventricular Dysfunction. The New England Journal of Medicine, 364, 1607-1616. https://doi.org/10.1056/NEJMoa1100356

[15] Veenhuyzen, G.D., Singh, S.N., McAreavey, D., Shelton, B.J. and Exner, D.V. (2001) Prior Coronary Artery Bypass Surgery and Risk of Death among Patients with Ischemic Left Ventricular Dysfunction. Circulation, 104, 1489-1493.

https://doi.org/10.1161/hc3801.096335

[16] Al-Khatib, S.M., Hellkamp, A.S., Lee, K.L., Anderson, J., Poole, J.E., Mark, D.B., et al. (2008) Implantable Cardioverter Defibrillator Therapy in Patients with Prior Coronary Revascularization in the Sudden Cardiac Death in Heart Failure Trial (SCD-HeFT). Journal of Cardiovascular Electrophysiology, 19, 1059-1065. https://doi.org/10.1111/j.1540-8167.2008.01191.x

[17] Funaro, S., La Torre, G., Madonna, M., Galiuto, L., Scarà, A., Labbadia, A., et al. (2009) Incidence, Determinants, and Prognostic Value of Reverse Left Ventricular Remodelling after Primary Percutaneous Coronary Intervention: Results of the Acute Myocardial Infarction Contrast Imaging (AMICI) Multicenter Study. European Heart Journal, 30, 566-575. https://doi.org/10.1093/eurheartj/ehn529

[18] Antoni, M.L., Mollema, S.A., Delgado, V., Atary, J.Z., Borleffs, C.J.W., Boersma, E., et al. (2010) Prognostic Importance of Strain and Strain Rate after Acute Myocardial Infarction. European Heart Journal, 31, 1640-1647. https://doi.org/10.1093/eurheartj/ehq105

[19] Austin, P.C. (2007) Propensity-Score Matching in the Cardiovascular Surgery Literature from 2004 to 2006: A Systematic Review and Suggestions for Improvement. The Journal of Thoracic and Cardiovascular Surgery, 134, 1128-1135. https://doi.org/10.1016/j.jtcvs.2007.07.021

[20] Grau, J.B., Ferrari, G., Mak, A.W.C., Shaw, R.E., Brizzio, M.E., Mindich, B.P., et al. (2012) Propensity Matched Analysis of Bilateral Internal Mammary Artery versus Single Left Internal Mammary Artery Grafting at 17-Year Follow-Up: Validation of a Contemporary Surgical Experience. European Journal of Cardio-Thoracic Surgery, 41, 770-775. 